\title{
İpek Kumaşların Bitki Yaprakları ile Bölgesel Desenlendirilmesi
}

\author{
Ramazan ERDEM ${ }^{*}$, Mine AYDOĞAN BAYRAM² ${ }^{2}$, Gülay BİLGE ${ }^{3}$, Onur ATAK ${ }^{4}$ \\ ${ }^{1}$ Akdeniz Üniversitesi, Serik Gülsün Süleyman Süral MYO, Tekstil Teknolojileri Bölümü, 07500, Antalya \\ ${ }^{2}$ Akdeniz Üniversitesi, Serik Gülsün Süleyman Süral MYO, Moda Tasarımı Bölümü, 07500, Antalya \\ ${ }^{3}$ Akdeniz Üniversitesi, Serik Gülsün Süleyman Süral MYO, Geleneksel Türk El Sanatları Bölümü, 07500, Antalya \\ ${ }^{4}$ Marmara Üniversitesi, Teknoloji Fakültesi, Tekstil Mühendisliği Bölümü, 34722, İstanbul
}

(Alınış / Received: 31.03.2017, Kabul / Accepted: 13.02.2018, Online Yayınlanma / Published Online: 03.05.2018)

Anahtar Kelimeler

Ekolojik baskl,

İpek,

Sürtme haslığı,

Yıkama haslığı,

Kumaș mukavemeti
Özet: Tekstil endüstrisinde yaș terbiye ișlemleri, çok fazla su tüketen, enerji girdilerinin yüksek olduğu ve atık bırakma potansiyeli yüksek seviyelerde olan süreçlerden olușmaktadır. Terbiye ișlemleri içinde yer alan baskı ile kumaș desenlendirme teknikleri ve teknolojileri, yenilikçi bakış açıları ile her geçen gün daha doğa dostu uygulamalar yönünde gelişim göstermektedir. Çalışmamızda, yeni bir desenlendirme yaklaşımı ile tamamen doğal malzemeler ve geleneksel metotlar kullanılarak ipek kumaşlar desenlendirilmiş ve kumaş performansları araştırılmıştır. Bunun için, ön işlem olarak 3 farklı yıkama reçetesi oluşturulmuştur. Sonrasında, kumaşlar şap taşı ve krem tartar kullanılarak mordanlanmıș ve yaș bitki yaprakları ile direkt olarak temas edecek şekilde kaynatma işlemi gerçekleştirilmiştir. Desenlendirmesi tamamlanan kumaşlar yıkama haslığı, sürtme haslığı, mukavemet ve uzama testlerine tabi tutularak pişirme, mordanlama ve bölgesel desenlendirme ișlemlerinin kumaș özellikleri üzerine etkileri belirlenmiștir.

\section{Local Patterning of Silk Fabric by using Plant Leafs}

\section{Keywords}

Ecological printing,

Silk,

Washing fastness, Rubbing fastness, Fabric tenacity

\begin{abstract}
Textile finishing processes use tremendous amount of water, consume much energy and create dramatic level of effluents. Printing is one of the finishing techniques, which is developing day by day with getting benefit from the innovative approaches to be more environment friendly application. In this study, silk fabrics have been patterned with plant leafs, and in the end, the performances of the fabrics have been investigated. First of all, three different scouring recipes have been prepared for the pretreatment of fabrics. Then, alum and cream of tartar have been used for mordanting. Next, fabrics, directly in contact with wet plant leafs, have been kept inside the boiling water for final patterning. At last, treated fabrics have been tested in terms of washing fastness, rubbing fastness, tenacity and elasticity in order to analyze the impact of scouring, mordanting and patterning processes on the fabric properties.
\end{abstract}

\section{Giriș}

Artan çevre bilinci ile birlikte, küresel ısınma, su kaynaklarının azalması ve kimyasal atık problemleri konularında yasal düzenlemeler arttırılmış, her sektördeki üretimin çevre dostu ölçütlere uygun olarak yapılması zorunluluğu ortaya çıkmıştır. Tekstil endüstrisinde atıkların \% 50'den fazlasının boyama, baskı ve bitim işlemlerinden kaynaklandığı bilinmektedir [1]. Çok fazla miktarda su, enerji, boyarmadde ve kimyasalların kullanılması tekstil bitim işlemlerinin ortaya çıkardığı kirlilik ve çevre yükünü arttırmaktadır.
Sentetik boyarmaddeler petrokimya kaynaklı olup, özellikle bazıları yapılarındaki birtakım kimyasal gruplar nedeniyle toksik ve kanserojen etki gösterebilmektedir. Örneğin, bazı azo boyarmaddelerin belli koşullar altında kanserojen aromatik aminler üretebileceği iddia edilmekte ve uzun süre ciltle temas halinde, cilt yoluyla emilerek ciddi sağlık sorunlarına yol açabileceği ifade edilmektedir. $\mathrm{Bu}$ sebeple 22 çeşit aril aminin kullanımı Avrupa Birliği tarafından yasaklanmıștır [2]. Ayrıca, dünya tekstil tüketiminin ortalama 30 milyon ton olduğu varsayılmakta ve bu rakamın her geçen yll \% 3 büyüme göstereceği öngörülmektedir. $\mathrm{Bu}$ da yaklaşık olarak her yıl ortalama 700.000 ton sentetik renklendiricinin doğayı kirletme riski 
taşıdığını göstermektedir [3]. Bu konuya atfen son yıllarda, Yeşil Tekstiller, Organik Tekstiller, Ekolojik Tekstiller, Çevre İçin Tasarım, Sürdürülebilirlik, Yaşam Döngüsü Değerlendirmesi- YDD (Life Cycle AssessmentLCA), Sürdürülebilir Tasarım (Design for Sustainability- D4S) gibi birçok kavram ortaya atılmış ve ekolojik tekstil tasarımı ile ilgili farkındalık yaratılmıştır [4-7].

İpekli kumaşlar parlak, sağlam, dökümlü ve yumuşak tutum özellikleri ile birçok kullanım alanında lüks tüketim ürünleri olarak tercih edilmektedir. Normal şartlar altında ham ipek bünyesinde su (\% 10-11), mineraller (\% 0.9-1.25), yağ ve mumlar (\% 0.45-0.9), fibroin (\% 64-73) ve serisin (\%17-25) proteinlerini barındırmaktadır. Fibroin esas ipek lifini, serisin ise bu lifleri saran zamk kısmını oluşturmaktadır (Şekil 1). Ham ipeği meydana getiren bu kimyasal karışımın oranı, ipek böceğinin çeşidine, beslenme biçimine ve yetiştiği ortamın koşullarına göre değişmektedir. İpek lifleri higroskopiktir. Asitlere karşı dayanıklıdır ancak bazlara karşı hassastır [8, 9].

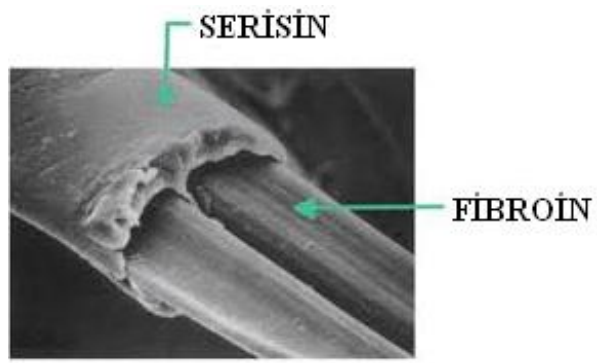

Şekil 1. İpek lifinin görüntüsü

Serisin, fibroin tabakasını dokuma ve örme sırasında meydana gelen sürtünme ve mekanik etkilere karşı korur, fakat liflerin daha mat görünmesine ve gevrek bir tutum sergilemesine neden olur. Serisin amorf yapısı, içerdiği bol miktarda hidroksil $(-\mathrm{OH})$ ve karboksil (-COOH) gruplar nedeniyle sicak su, asitler, bazlar ve enzimlerle muamele edilerek kolaylıkla uzaklaştırılabilmektedir. Enzimatik serisin giderme işlemi oldukça hızlı bir yöntem olmasına rağmen sıcaklık, pH, işlem süresi, enzim konsantrasyonu, deterjan tipi, ipeğin cinsi/kalitesi ve kullanılan makine gibi unsurlara dikkat edilmediği takdirde liflerin zarar görmesine neden olan bir yöntemdir [10].

Geleneksel olarak sabunla serisin uzaklaştırma yönteminde liflerin zarar görme ihtimalleri diğer yöntemlere göre daha düşüktür. Bununla birlikte, ișlem süresi daha uzundur. Chopra ve arkadașları, Mulberry ipekli kumaş örneklerinden asit, alkali, trietilenamin (TEA), sabun ve enzim ile işlemi kapsayan beş farklı yöntem ile serisini uzaklaştırmışlardır. Tutum özellikleri açısından numuneler karşılaştırıldığında, sabun, alkali ve TEA metotları ile elde edilen sonuçlar, asidik ve enzimatik metotlara göre daha tatmin edici bulunmuştur. Asit ve enzimlerle yapılan muamelelerde kumaşların özellikle iplik kesișim bölgelerinde serisinden arındırmanın yeterince homojen olmadığı tespit edilmiştir [11].

İpek lifleri amfoterik bir yapıya sahip olmaları nedeniyle, anyonik, katyonik, direkt, reaktif ve metal kompleks boyarmaddeleri ile kolaylıkla boyanabilmekte ya da bask ile desenlendirilebilmektedir. Bahsi geçen boyarmaddelerin haslık değerlerinde, uygulanma sürelerinde ve maliyetlerinde farklılıklar söz konusudur. Endüstride bu boyarmaddeler ile gerçekleştirilen baskı teknikleri; direkt baskı, aşındırma baskı, rezerve baskı, transfer baskı, ink-jet baskı ve özel baskılar (flok, gofre, batik, krep, devore vb.) olarak gruplandırılabilir. Uygulama esnasında tüketilen su, harcanan enerji ve çevreye bırakılan atık miktarı düşündürücü boyutta olup, doğa dostu uygulamaların geliștirilmesi yönünde çalışmalar devam etmektedir [12].

Bitki yaprakları veya çiçeklerinin direkt olarak kumaş ile teması yoluyla desenlendirme esasına dayanan yöntem ise yeni bir doğal uygulama olarak karşımıza çlkmaktadır. Bununla birlikte literatürde bu konu ile ilgili çalışmaların sayısı çok azdır. Sherry Haar yapmış olduğu çalışmada, yaş, kuru veya dondurulmuş haldeki sumak, demirağacı yaprağı, altınbaşak, mazı ve portakal yapraklarını mordanlanmış kumaşların yüzeyine yerleştirmiş ve bu kumaşları katlayıp sıkıca bağladıktan sonra plastik torbalarda birkaç gün boyunca güneş ışığına maruz bırakmıştır [13]. Oldukça tatmin edici sonuçlara ulaşılmasına rağmen, gün içindeki ısı ve 1 şı miktarındaki farklılıklar aynı verimlilikte desenlendirme yapmanın önünde engeldir [14].

Avustralyalı sanatçı India Flint okaliptus yapraklarını yünlü, pamuklu ve ipekli kumaşlara çekiç darbeleri ile ezerek direkt olarak uygulamıș, farklı tonlarda rastgele desenler elde etmiştir [15]. Bu yöntemde, darbe alan kumaşların mekanik özelliklerinin kötüleşme ihtimali söz konusudur.

$\mathrm{Bu}$ çalıșmada, özgün bir yöntem olan direkt temas tekniği ile ipekli kumaşlar herhangi bir mekanik kuvvet ya da güneş ışığına maruz bırakmaya gerek kalmadan, sadece sıcak suda kaynatma yöntemi ile desenlendirilmiştir. Renklendirme için yaş bitki yaprakları kullanılmıştır. Baskılı kumaşların renk ölçümleri yapılmış, yıkama haslığı, sürtme haslığı, mukavemet ve uzama özellikleri test edilmiştir.

\section{Materyal ve Metot}

\subsection{Materyal}

$\mathrm{Bu}$ çalışmada $50 \mathrm{~g} / \mathrm{m}^{2}$ ağırlığında atkı sıklığı 30 tel/cm, çözgü sıklı̆̆ ise 35 tel/cm olan, B 1/1 (Bez ayağı) bağlantısında dokunmuş vual ipek kumaş ile çalışılmıştır. Zamk çıkarma (serisin uzaklaştırma) işlemi için yeşil sabun ve sodyum bikarbonat $\left(\mathrm{NaHCO}_{3}\right)$, mordanlama için ise şap taşı 
$\left[\mathrm{KAl}\left(\mathrm{SO}_{4}\right)_{2} .12 \mathrm{H}_{2} \mathrm{O}\right]$ ve krem tartar $\left(\mathrm{KC}_{4} \mathrm{H}_{5} \mathrm{O}_{6}\right)$ kullanılmıștır.

\subsection{Bölgesel desenlendirme öncesi kumaşların yıkanması}

Yıkama işlemi için üç farklı yıkama reçetesi (A, B, C) olușturulmuștur. Yıkamada ve durulamalarda kullanılan su, ESC Reverse Osmosis Systems (ESC Ltd. Şti., Antalya, Türkiye) marka arıtıcıda arıtılmıştır. Yapılan analizlerde sudaki Ca miktarı 1-2 Fr., ağır metallerin miktarı ise TDS ölçüm cihazında 23 olarak bulunmuştur (șebeke suyunda bu değer 350-400 civarındadır). Yıkama reçetesinin içeriği ve işlem parametreleri ile ilgili detaylar Tablo 1'de sunulmaktadır. Her bir grupta 4 adet olacak șekilde 31 x $31 \mathrm{~cm}$ ebatlarında toplam 12 adet ipek kumaş hazırlanmıştır. Yeşil sabun ve sodyum bikarbonatın, ipek kumaşların boya çekme kapasitelerine etkisini ölçümlemek amacıyla bu iki maddenin her bir grup için banyoya katılma miktarları değiştirilmiştir.

Tablo 1.Yıkama ve işlem parametreleri

\begin{tabular}{ccccc}
\hline Reçete & $\begin{array}{c}\text { Yeşil } \\
\text { Sabun } \\
\text { (g) }\end{array}$ & $\begin{array}{c}\text { Sodyum } \\
\text { bikarbonat } \\
\text { NaHCO }_{\mathbf{3}}(\mathbf{g})\end{array}$ & $\begin{array}{c}\text { Toplam } \\
\text { Süre } \\
\text { (dk) }\end{array}$ & $\begin{array}{c}\text { Sicaklık } \\
\mathbf{0}^{\mathbf{C}}\end{array}$ \\
\hline $\mathrm{A}$ & 30 & 2,5 & 70 & $40-100$ \\
$\mathrm{~B}$ & 45 & 5 & 70 & $40-100$ \\
$\mathrm{C}$ & 60 & 7,5 & 70 & $40-100$ \\
\hline
\end{tabular}

A, B ve C gruplarına uygulanan yıkama işlemleri ise metodolojik olarak aynı tutulmuştur. Kumaşlar, 5 litre su içerisinde ilk 10 dakika boyunca $40{ }^{\circ} \mathrm{C}$ 'de karıştırılarak bekletilmiștir. Daha sonra yeșil sabun ilavesi yapılmış ve $15 \mathrm{dk}$ kadar yine $40{ }^{\circ} \mathrm{C}^{\prime} \mathrm{de}$ karıștırılarak bekletilmiștir. Sonrasında, banyoya $\mathrm{NaHCO}_{3}$ ilave edilmiş ve kumaşlar $100{ }^{\circ} \mathrm{C}^{\prime} \mathrm{de} 45 \mathrm{dk}$ kadar kaynatılmıștır. Ardından, sıcak ve soğuk durulamalar yapılarak yıkama işlemi tamamlanmıştır (Şekil 3). Kumaşlar mordanlama işlemi öncesi oda sıcaklığında 24 saat asarak kurutulmuştur.

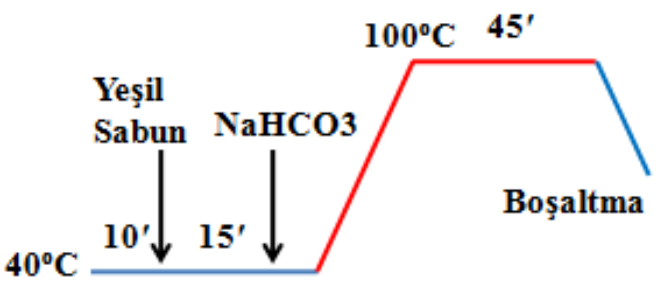

Şekil 3.Yıkama işlemi

\subsection{Mordanlama işlemi}

Her bir grup için ayrı ayrı olmak kaydıyla mordanlama işlemi 1 litre su içerisinde $5 \mathrm{~g}$ şap $\left[\mathrm{KAl}\left(\mathrm{SO}_{4}\right)_{2} \cdot 12 \mathrm{H}_{2} \mathrm{O}\right]$ ve $1,5 \mathrm{~g}$ krem tartar $\left(\mathrm{KC}_{4} \mathrm{H}_{5} \mathrm{O}_{6}\right)$ çözüldükten sonra, kumaşların bu çözelti içerisinde $40{ }^{\circ} C^{\prime}$ de 1 saat bekletilmesiyle gerçekleştirilmiştir. Daha sonra kumaşlar bölgesel desenlendirme işlemi öncesi gün ışığı almayan bir ortamda oda sıcaklığında 24 saat asarak kurutulmuştur.

\subsection{Yaş bitki yaprakları ile bölgesel desenlendirme işlemi}

Direkt temas yöntemi ile renklendirme çalışmamızda yaş haldeki okaliptus, zeytin, gül, çam, meşe palamutu ve sinerya yaprakları kullanılmıștır (Şekil 2).

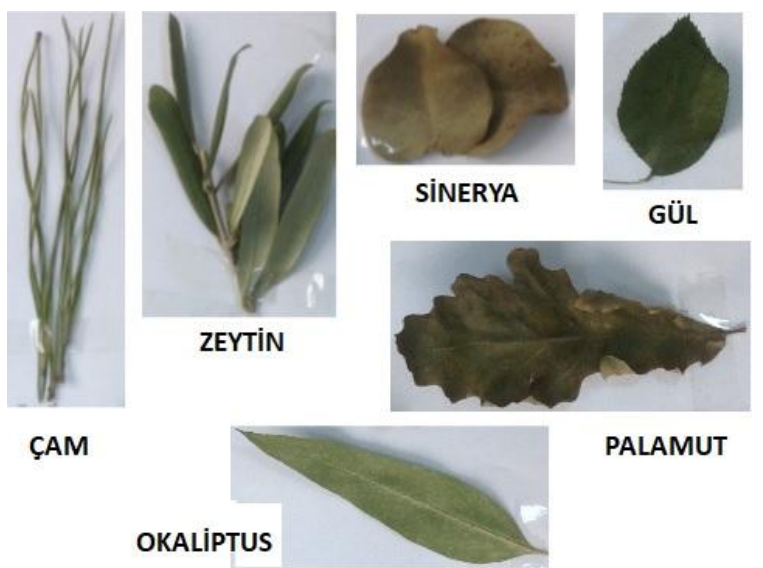

Şekil 2. Bölgesel desenlendirme için kullanılan yaprak resimleri.

Yapraklar, sirke (asetik asit) / su (1:1) karışımına daldırıldıktan sonra, kumaşın bir tarafına sistematik bir biçimde dizilmişlerdir. Simetrik desenler elde etmek üzere, kumaşın boş kalan tarafi, yaprakların dizildiği dolu tarafın üzerine katlanmıştır. Daha sonra, katlı kumaşlar, çapı yaklaşık $1.5 \mathrm{~cm}$, boyu ise yaklaşık $20 \mathrm{~cm}$ olan düzgün tahta çubukların etrafına rulo șeklinde sıkıca sarılmıștır. Ruloların açılmaması için, kumaşların etrafına keten iplikleri sıkıca dolanmıștır. Sonrasında bu yıkama teknesinde arıtılmıș su ile 1 saat boyunca kaynatılmıștır. Kaynatma ișlemi tamamlandıktan sonra rulolar açılarak temizlenmiş ve kumaşlar gün ışığı olmayan ortamda oda sicaklığında 24 saat boyunca asarak kurutulmuştur. Son olarak, her gruptan üçer adet kumaşa üstten rezistans ısıtmalı kapalı firında (Elit Makine, Türkiye) farklı sıcaklıklarda fiksaj ișlemi uygulanmıştır (Tablo 2).

Tablo 2. Fikse ișlemi parametreleri

\begin{tabular}{cccc}
\hline Numuneler & A1, B1, C1 & A2, B2, C2 & A3, B3, C3 \\
\hline Sıcaklık $\left({ }^{0} \mathrm{C}\right)$ & 110 & 120 & 130 \\
Süre $(\mathrm{dk})$ & 4 & 4 & 4 \\
\hline
\end{tabular}

\subsection{Renk ölçümleri}

Bölgesel desenlendirme işlemi yapılmış materyale ait renk ölçümleri, SI modunda ve LAV (6.6 mm) ölçüm plakası ile $\mathrm{D}_{65}$ lambası ve $10^{\circ}$ standart gözlemciye göre Spectraflash SF 600 + reflektans spektrometresi kullanılarak gerçekleştirilmiștir. Yapılan ölçümler sonucu CIELab (Uluslararası Aydınlatma Komisyonu) renk koordinat değerleri elde edilmiștir. CIELab renk uzayında $L^{*}$, rengin parlaklığını (açıklık-koyuluk), a* kırmızı-yeşil renk ekseni ve $b^{*}$ ise sarı-mavi eksen değerini ifade etmektedir. Ayrıca $\mathrm{C}^{*}$, nötral noktadan $\left(\mathrm{a}^{*}=\mathrm{b}^{*}=0\right)$ uzaktaki kromayı (doygunluk) ve $\mathrm{h}$ ise renk tonunun açısal değerini göstermektedir [16]. 


\subsection{Yıkama ve sürtme haslığı testleri}

Bölgesel desenlendirme işlemi yapılmış kumaş numuneleri, ISO 105-C06 yıkamaya karşı renk haslığı standardının A1S koşuluna göre, $40{ }^{\circ} \mathrm{C}$ sıcaklıkta, 10 adet bilye ve 30 dakika süre ile yıkama haslığı testine [17] tabi tutulmuştur. Ayrıca, yine bölgesel desenlendirme işlemi yapılmış kumaş numunelerine TS 717 EN ISO 105-X12 standardına göre sürtünmeye karşı renk haslığı testi yapılmıştır [18].

\subsection{Mukavemet ve uzama testi}

Kumaş numunelerin mekanik özelliklerini incelemek üzere Instron (Instron 4411) marka universal test cihazı kullanılmıştır. Numuneler çözgü yönü ve atkı yönünde olmak üzere iki farklı şekilde ve 15 x $5 \mathrm{~cm}$ (boy $\mathrm{x}$ en) ölçülerinde kesilmiştir. Numuneleri koparmak için $5 \mathrm{kN}$ (kiloNewton)'luk kuvvet uygulanmıştır. Piston hızı $100 \mathrm{~mm} / \mathrm{dk}$ olarak ayarlanmıștır. Yük değerleri ' $\mathrm{kg}$ ' cinsinden okunmuştur. Uzama değerleri ise 'mm' olarak kaydedilmiş ve daha sonra '\%' olarak hesaplanmıştır. Her bir numune için 3 tekrar yapılmıştır.

\section{Bulgular}

\subsection{Kumaş görüntüleri}

Yıkama işlemlerinde kullanılan yeşil sabun ve sodyum bikarbonat miktarını artması ile desenlendirme sonrası bir miktar daha net desenler elde edilmiştir. Şekil 4'de fikseli ve fiksesiz gruplara ait desenlendirilmiş kumaş örnekleri görülmektedir. Desenler net çımasına rağmen, yaş haldeki yapraklarla elde edilen renklerin desenlerin her yerinde eşit tonlar ile dağılmadığı görülmüștür. Bundan dolayı kısmen de olsa her bir yaprak için desenlerde bir renklenme meydana geldiğinden ortalama CIELab değerleri ile renkler matematiksel olarak ifadelendirilmiştir. Desenlendirme sonrası okaliptus, meșe palamutu, gül, sinerya ve zeytin yapraklarından elde edilen renkler Tablo 3, Tablo 4, Tablo 5, Tablo 6 ve Tablo 7'de CIELab değerleri olarak verilmiştir.

Tablo 3. Okaliptus yaprağı ile yaplan bölgesel desenlendirme işlemi sonucu elde edilen renklerin ölçüm sonuçları (CIELab değerleri); FA: Fiksesiz A, FB. Fiksesiz B, FC: Fiksesiz C.

\begin{tabular}{|l|l|l|l|l|l|l|l|}
\hline Kod & $\mathrm{L}^{*}$ & $\mathrm{a}^{*}$ & $\mathrm{~b}^{*}$ & $\mathrm{C}^{*}$ & $\mathrm{~h}^{*}$ & $\mathrm{x}$ & $\mathrm{y}$ \\
\hline FA & 59.55 & 3.10 & 13.48 & 13.83 & 77.05 & 0.35 & 0.36 \\
\hline A1 & 58.29 & 3.45 & 14.32 & 14.73 & 76.45 & 0.36 & 0.37 \\
\hline A2 & 53.14 & 3.82 & 13.41 & 13.94 & 74.11 & 0.36 & 0.37 \\
\hline A3 & 63.72 & 2.55 & 15.07 & 15.28 & 80.40 & 0.36 & 0.37 \\
\hline FB & 73.07 & -0.4 & 23.42 & 23.42 & 90.98 & 0.36 & 0.38 \\
\hline B1 & 67.41 & 0.67 & 24.35 & 24.36 & 88.42 & 0.37 & 0.39 \\
\hline B2 & 64.80 & 1.91 & 17.21 & 17.31 & 83.68 & 0.36 & 0.37 \\
\hline B3 & 64.93 & 1.58 & 13.31 & 13.41 & 83.22 & 0.35 & 0.36 \\
\hline FC & 61.60 & 2.10 & 14.17 & 14.33 & 81.57 & 0.35 & 0.37 \\
\hline C1 & 65.09 & 1.12 & 20.00 & 20.03 & 86.80 & 0.36 & 0.38 \\
\hline C2 & 64.97 & 1.78 & 17.18 & 17.28 & 84.08 & 0.36 & 0.37 \\
\hline C3 & 67.56 & 1.36 & 18.88 & 18.93 & 85.89 & 0.36 & 0.38 \\
\hline
\end{tabular}

Çam yapraklarından ise desenlendirme ișlemi sonrası herhangi bir renk elde edilememiştir. $\mathrm{C}$ grubuna ait numunelerde, A ve B gruplarına ait numunelere göre desenlerin bir miktar daha net çıktığı söylenebilir. Bu durumun, $\mathrm{C}$ grubunun yıkanmasında kullanılan yeşil sabun ve $\mathrm{NaHCO}_{3}$ miktarının fazla olması dolayısıyla serisinin diğer gruplara göre bir miktar daha fazla uzaklaşmasından kaynaklandığı söylenebilir [19].

Tablo 4. Meșe palamutu yaprağı ile yapılan bölgesel desenlendirme işlemi sonucu elde edilen renklerin ölçüm sonuçları (CIELab değerleri); FA: Fiksesiz A, FB. Fiksesiz B, FC: Fiksesiz C.

\begin{tabular}{|c|l|l|l|l|l|l|l|}
\hline Kod & $\mathrm{L}^{*}$ & $\mathrm{a}^{*}$ & $\mathrm{~b}^{*}$ & $\mathrm{C}^{*}$ & $\mathrm{~h}^{*}$ & $\mathrm{x}$ & $\mathrm{y}$ \\
\hline FA & 63.11 & 3.75 & 12.83 & 13.37 & 73.70 & 0.35 & 0.36 \\
\hline A1 & 70.11 & 3.07 & 9.58 & 10.06 & 72.21 & 0.34 & 0.35 \\
\hline A2 & 71.28 & 4.01 & 10.98 & 11.69 & 69.95 & 0.35 & 0.35 \\
\hline A3 & 75.95 & 1.67 & 11.97 & 12.08 & 82.04 & 0.34 & 0.36 \\
\hline FB & 60.68 & 4.14 & 9.42 & 10.29 & 66.26 & 0.35 & 0.35 \\
\hline B1 & 62.62 & 3.59 & 9.28 & 9.95 & 68.84 & 0.34 & 0.35 \\
\hline B2 & 75.03 & 2.95 & 12.20 & 12.55 & 76.38 & 0.34 & 0.36 \\
\hline B3 & 61.25 & 3.97 & 11.66 & 12.32 & 71.19 & 0.35 & 0.36 \\
\hline C & 66.71 & 2.16 & 9.11 & 9.36 & 76.67 & 0.34 & 0.35 \\
\hline C1 & 58.74 & 4.19 & 14.20 & 14.81 & 73.54 & 0.36 & 0.36 \\
\hline C2 & 76.01 & 2.94 & 12.15 & 12.56 & 76.01 & 0.35 & 0.36 \\
\hline C3 & 67.14 & 3.70 & 13.40 & 13.90 & 74.56 & 0.35 & 0.36 \\
\hline
\end{tabular}

Tablo 5. Gül yaprağı ile yapılan bölgesel desenlendirme işlemi sonucu elde edilen renklerin ölçüm sonuçları (CIELab değerleri); FA: Fiksesiz A, FB. Fiksesiz B, FC: Fiksesiz C.

\begin{tabular}{|l|l|l|l|l|l|l|l|}
\hline Kod & $\mathrm{L}^{*}$ & $\mathrm{a}^{*}$ & $\mathrm{~b}^{*}$ & $\mathrm{C}^{*}$ & $\mathrm{~h}^{*}$ & $\mathrm{x}$ & $\mathrm{y}$ \\
\hline FA & 71.31 & -1.46 & 24.48 & 24.52 & 93.41 & 0.37 & 0.39 \\
\hline A1 & 72.51 & -2.48 & 20.57 & 20.72 & 96.86 & 0.35 & 0.38 \\
\hline A2 & 70.93 & -2.07 & 15.43 & 15.57 & 97.63 & 0.34 & 0.37 \\
\hline A3 & 71.03 & -3.78 & 19.86 & 20.22 & 100.78 & 0.35 & 0.38 \\
\hline FB & 73.33 & -2.78 & 22.51 & 23.97 & 96.45 & 0.36 & 0.37 \\
\hline B1 & 81.37 & -3.95 & 21.65 & 22.00 & 100.34 & 0.35 & 0.38 \\
\hline B2 & 59.99 & -2.11 & 15.74 & 15.88 & 97.64 & 0.35 & 0.38 \\
\hline B3 & 76.91 & -1.46 & 21.71 & 21.76 & 93.84 & 0.36 & 0.38 \\
\hline FC & 74.89 & -0.32 & 13.24 & 13.25 & 91.37 & 0.34 & 0.36 \\
\hline C1 & 65.12 & -0.74 & 15.28 & 15.29 & 92.76 & 0.35 & 0.37 \\
\hline C2 & 80.65 & -4.92 & 26.15 & 26.60 & 100.65 & 0.36 & 0.39 \\
\hline C3 & 69.35 & -1.83 & 23.74 & 23.81 & 94.42 & 0.36 & 0.39 \\
\hline
\end{tabular}

Tablo 6. Sinerya yaprağı ile yapılan bölgesel desenlendirme ișlemi sonucu elde edilen renklerin ölçüm sonuçları (CIELab değerleri); FA: Fiksesiz A, FB. Fiksesiz B, FC: Fiksesiz C.

\begin{tabular}{|l|l|l|l|l|l|l|l|}
\hline Kod & $\mathrm{L}^{*}$ & $\mathrm{a}^{*}$ & $\mathrm{~b}^{*}$ & $\mathrm{C}^{*}$ & $\mathrm{~h}^{*}$ & $\mathrm{x}$ & $\mathrm{y}$ \\
\hline FA & 64.75 & 15.17 & 23.98 & 28.38 & 57.69 & 0.40 & 0.37 \\
\hline A1 & 65.68 & 8.57 & 21.60 & 23.24 & 68.36 & 0.38 & 0.37 \\
\hline A2 & 72.39 & 9.66 & 25.01 & 26.81 & 68.88 & 0.39 & 0.38 \\
\hline A3 & 66.33 & 14.76 & 26.07 & 29.96 & 60.49 & 0.40 & 0.38 \\
\hline FB & 67.34 & 13.80 & 25.50 & 28.99 & 61.58 & 0.40 & 0.38 \\
\hline B1 & 60.09 & 10.47 & 21.75 & 24.14 & 64.30 & 0.39 & 0.38 \\
\hline B2 & 58.25 & 7.19 & 22.41 & 23.54 & 72.20 & 0.39 & 0.38 \\
\hline B3 & 59.75 & 7.23 & 21.41 & 22.60 & 71.34 & 0.38 & 0.35 \\
\hline FC & 64.24 & 16.26 & 22.80 & 28.01 & 54.51 & 0.40 & 0.37 \\
\hline C1 & 68.38 & 11.02 & 19.26 & 22.19 & 60.23 & 0.38 & 0.37 \\
\hline C2 & 67.34 & 12.61 & 29.27 & 31.87 & 66.70 & 0.41 & 0.39 \\
\hline C3 & 70.57 & 10.59 & 18.51 & 21.32 & 60.23 & 0.37 & 0.36 \\
\hline
\end{tabular}

\subsection{Yıkama ve sürtme haslığı test sonuçları}

Numune kumaşların kuru ve yaş sürtünme haslığı değerleri Tablo 8'de verilmiștir. Farklı reçetelere göre desenlendirme işlemi yapılmış kumaşların kuru ve 
yaş sürtme haslık test sonuçları iyi çıkmıştır. A grubu için haslık değerlerinde çok az da olsa bir iyileşme olmuştur. Sürtme haslığı anlamında, artan fiksaj sıcaklıklarının kumaş performanslarına kayda değer bir katkısının olmadığı anlaşılmıştır.

Tablo 7. Zeytin yaprağı ile yapılan bölgesel desenlendirme işlemi sonucu elde edilen renklerin ölçüm sonuçları (CIELab değerleri); FA: Fiksesiz A, FB. Fiksesiz B, FC: Fiksesiz C.

\begin{tabular}{|l|l|l|l|l|l|l|l|}
\hline Kod & $\mathrm{L}^{*}$ & $\mathrm{a}^{*}$ & $\mathrm{~b}^{*}$ & $\mathrm{C}^{*}$ & $\mathrm{~h}^{*}$ & $\mathrm{x}$ & $\mathrm{y}$ \\
\hline FA & 77.22 & -1.1 & 26.21 & 26.23 & 92.42 & 0.37 & 0.39 \\
\hline A1 & 74.05 & 0.49 & 27.00 & 27.01 & 91.11 & 0.37 & 0.38 \\
\hline A2 & 73.06 & 0.39 & 26.92 & 26.92 & 89.16 & 0.37 & 0.39 \\
\hline A3 & 72.04 & 0.29 & 18.51 & 18.51 & 89.10 & 0.36 & 0.37 \\
\hline FB & 85.08 & 0.44 & 10.76 & 10.77 & 87.67 & 0.34 & 0.35 \\
\hline B1 & 81.45 & -1 & 18.96 & 18.98 & 93.13 & 0.35 & 0.37 \\
\hline B2 & 79.00 & -1 & 19.03 & 19.16 & 93.01 & 0.35 & 0.36 \\
\hline B3 & 78.53 & -1 & 19.17 & 19.20 & 93.10 & 0.35 & 0.37 \\
\hline FC & 73.65 & 1.2 & 35.43 & 35.45 & 88.06 & 0.39 & 0.41 \\
\hline C1 & 79.01 & -0.5 & 21.80 & 21.81 & 91.39 & 0.36 & 0.38 \\
\hline C2 & 86.46 & -2.2 & 18.09 & 18.22 & 96.93 & 0.34 & 0.37 \\
\hline C3 & 77.65 & 0.93 & 25.99 & 26.00 & 87.96 & 0.37 & 0.39 \\
\hline
\end{tabular}

Tablo 8. Bölgesel desenlendirme işlemi yapılmış kumaşlara ait sürtünme haslığı test sonuçları

\begin{tabular}{|c|c|c|}
\hline Reçete & Kuru & Yaş \\
\hline Fiksesiz A & $4-5$ & 4 \\
\hline Fiksesiz B & $4-5$ & $4-5$ \\
\hline Fiksesiz C & $4-5$ & $4-5$ \\
\hline A1 & 5 & 5 \\
\hline B1 & 5 & 5 \\
\hline C1 & 5 & 5 \\
\hline A2 & 5 & 5 \\
\hline B2 & 5 & 5 \\
\hline C2 & 5 & 5 \\
\hline A3 & 5 & 5 \\
\hline B3 & 5 & 5 \\
\hline C3 & 5 & 5 \\
\hline
\end{tabular}
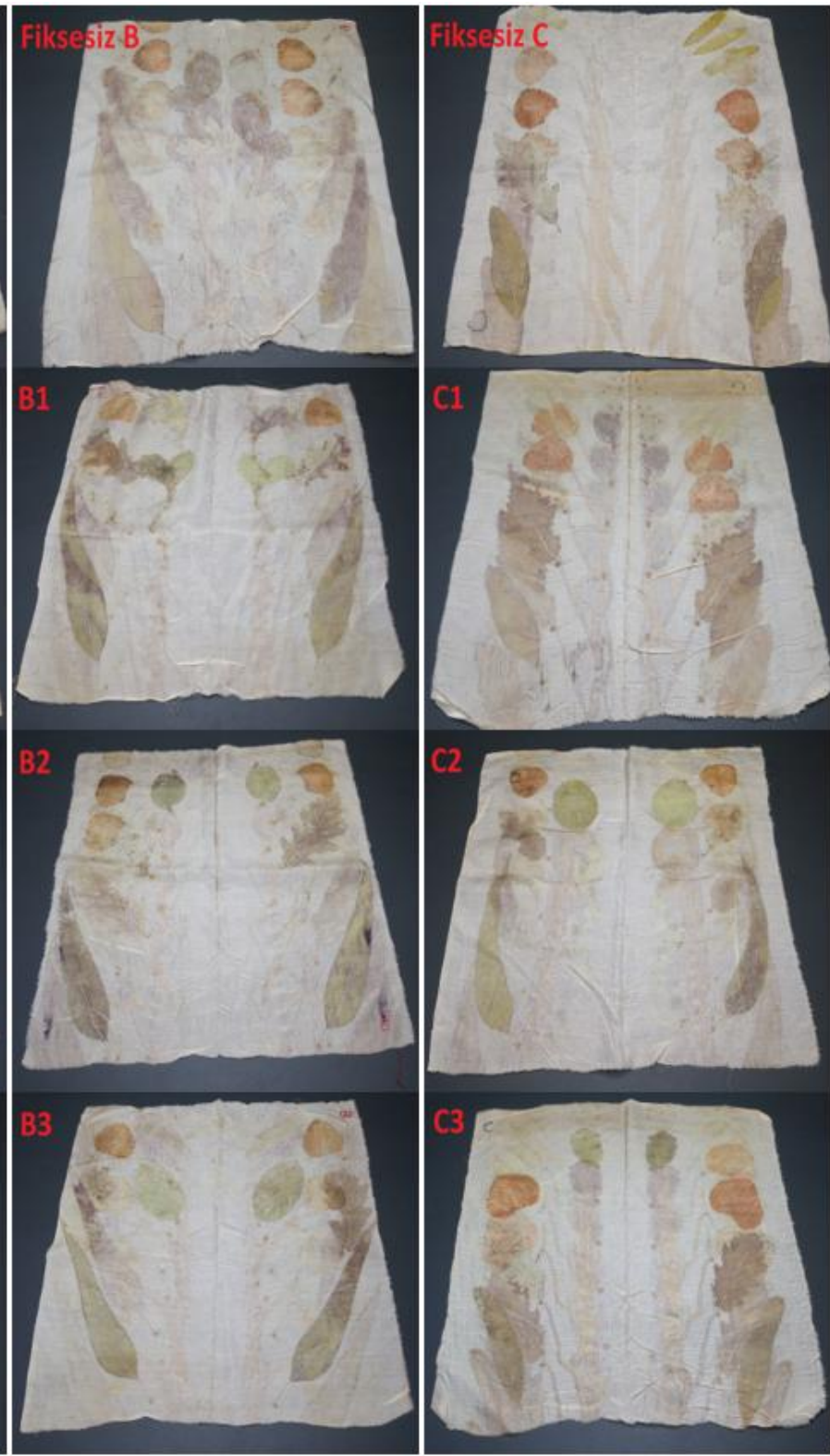

Şekil 4. Fikseli ve fiksesiz kumaş görüntüleri 
Belirtilen koşullara göre gerçekleştirilmiş olan yıkamaya karşı renk haslığı testi (Lekeleme) sonuçları Tablo 9'da verilmektedir. Bölgesel desenlendirme işlemi yapılmış kumaşların yıkama haslığı test sonuçlarına göre lekeleme değerlerinin farklı reçeteler için iyi olduğu gözlenmiştir. Ayrıca, fiskeli kumaşların haslık değerleri, fiskesizlere göre çok az da olsa daha iyi çıkmıştır. Sürtme ve yıkama haslık sonuçları, yapılan bölgesel desenlendirme işleminin, ilave bir fikse işlemi gerektirmeyecek kadar başarılı olduğunu ortaya koymuştur.

\subsection{Mukavemet ve uzama test sonuçları}

Şekil 5'de bölgesel desenlendirme yapılan ve yapılmayan (kontrol) kumaşların mukavemet sonuçları verilmektedir. Genel olarak, dokuma kumaşların çözgü yönündeki mukavemet değerleri, atkı yönündeki mukavemet değerlerinden daha yüksek bulunmuştur. Elde edilen sonuçlara göre, hiç işlem görmemiş ham (kontrol) kumaşların mukavemetleri hem çözgü yönünde (ortalama $37 \pm 2$ $\mathrm{kg}$ ) hem de atkı yönünde (ortalama $35 \pm 1.5 \mathrm{~kg}$ ) diğer işlem görmüş kumaşların mukavemetlerinden daha yüksek bulunmuştur. Yıkama ve desenlendirme işlemlerine tabi tutulan kumaşlarda çok olmasa da belli bir miktar kayıp olduğu gözlenmiștir. Serisinden farklı olarak fibroin suda çözünmemekte ancak kaynar su veya buharla uzunca süre işlem gören ipek liflerindeki makromoleküllerin, peptid bağlarındaki hidroliz nedeniyle, parçalanabilme ihtimalinin olduğu bilinmektedir. Bununla birlikte, ipek liflerinin asitler ile muamelesinde molekül zincirlerinde bulunan amino asit miktarında bir miktar kayıp olabileceği daha önceki çalışmalarda ifade edilmiştir [8].

Ayrıca, bazı alkali ve toprak alkali metallerin tuzlarının ipek liflerini şişirdiği ve hatta kısmen çözecek şekilde etki gösterebildiği iddia edilmiştir [8]. Tüm bu verilerin ışığında, çalışmamızda işlem gören ipek kumaşların işlem görmeyen kumaşlara göre daha az mukavemetli bulunması literatürdeki sonuçlar ile uyumluluk göstermiştir. İlave olarak, grafik incelendiğinde, fikse sıcaklığı yükseldikçe bir miktar daha mukavemet kaybı yaşandığı görülmüştür. En düşük mukavemet sonuçları C3 kodlu numune için elde edilmiştir (çözgü yönü, $25 \pm 1.7 \mathrm{~kg}$; atkı yönü, $23 \pm 1.68 \mathrm{~kg}$ ).

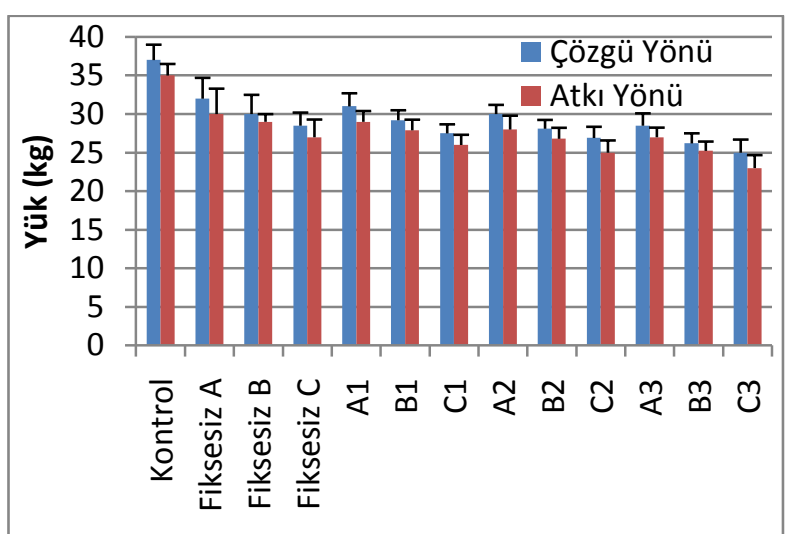

Şekil 5. Bölgesel desenlendirme yapılan ve yapılmayan (kontrol) kumaşların mukavemet test sonuçları

Literatürdeki bazı çalışmalarda, pişirme ile serisin uzaklaştırma işlemi süresince, ipekte kirlilik, sararma, incelme ve sertleşme gibi problemlerin söz konusu olabileceği belirtilmiştir [20, 21]. Çalışmalarımızda, yıkama, mordanlama ve desenlendirme işlemleri sonrasında kumaş numunelerinde bir mikar (ham kumaş beyazlık indeksi 74; işlem görmüş kumaş beyazlık indeksi 46.6) kirlenme ve sararma meydana gelmiștir ve bir miktar esneklik kaybı olduğu tespit edilmiştir. Şekil 6'da bölgesel desenlendirme yapılan ve yapılmayan (kontrol) kumaşların \% uzama değerleri verilmektedir. Grafiğe göre, en yüksek uzama değerleri (çözgü yönü, \%24 $\%$; atkı yönü, \% $25 \pm 0.87$ ) kontrol numunelerinde, en düşük uzama değerleri (çözgü yönü, \% 19.2 \pm 0.88 ; atkı yönü yönü, \% 19.7 \pm 0.76 ) ise C3 kodlu numunelerde elde edilmiştir. Ön terbiye işlemi esnasında kullanılan yıkama maddelerinin miktarlarının artması nedeniyle kumașlardaki serisin miktarının azalması ihtimali ve fikse sıcaklıklarının yüksekliği, \% uzama değerlerini olumsuz yönde etkilemiştir denebilir. Ayrıca, kumaşların atkı yönündeki uzama değerleri çözgü yönünde ölçülen değerlerden daha yüksek bulunmuştur.

Tablo 9. Baskı ișlemi yapılmıș kumașlara ait yıkamaya karșı renk haslı̆̆ı test sonuçları lekeleme değerleri

\begin{tabular}{|c|c|c|c|c|c|c|}
\hline & YÜN & AKRILIKK & POLIESTER & POLİAMID & PAMUK & SATETAT \\
\hline Reçete & & & & & & \\
\hline Fiksesiz A & $4-5$ & $4-5$ & $4-5$ & $4-5$ & $4-5$ & $4-5$ \\
\hline Fiksesiz B & $4-5$ & $4-5$ & $4-5$ & $4-5$ & $4-5$ & $4-5$ \\
\hline Fiksesiz C & $4-5$ & $4-5$ & $4-5$ & $4-5$ & $4-5$ & $4-5$ \\
\hline A1 & 5 & 5 & 5 & 5 & 5 & 5 \\
\hline B1 & 5 & 5 & 5 & 5 & 5 & 5 \\
\hline C1 & 5 & 5 & 5 & 5 & 5 & 5 \\
\hline A2 & 5 & 5 & 5 & 5 & 5 & 5 \\
\hline B2 & 5 & 5 & 5 & 5 & 5 & 5 \\
\hline A3 & 5 & 5 & 5 & 5 & 5 & 5 \\
\hline B3 & 5 & 5 & 5 & 5 & 5 & 5 \\
\hline C3 & 5 & 5 & 5 & 5 & 5 & 5 \\
\hline
\end{tabular}




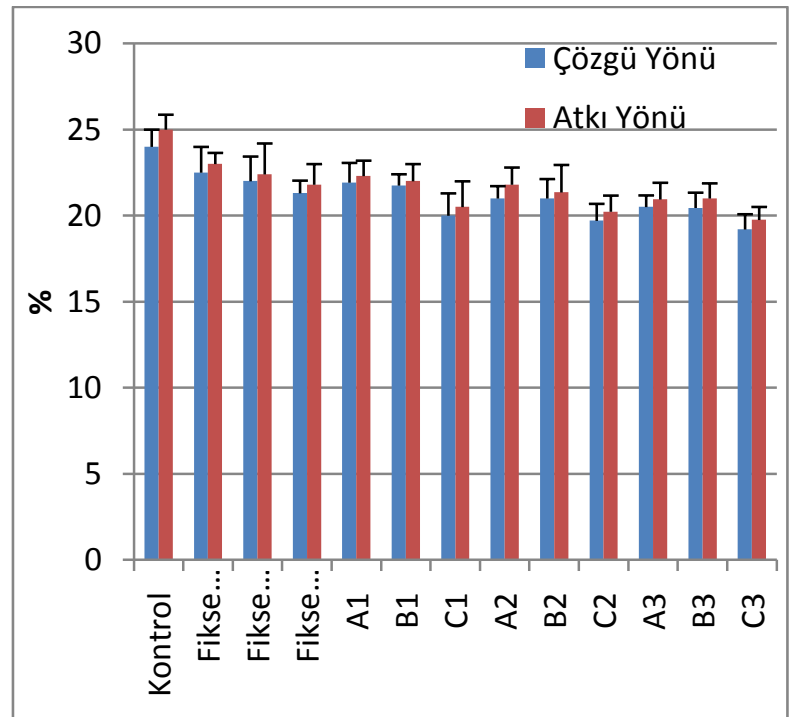

Şekil 6. Bölgesel desenlendirme yapılan ve yapılmayan (kontrol) kumaşların \% uzama test sonuçları

\section{Tartışma ve Sonuç}

Bu çalışma ile çevre dostu bir uygulamayla otantik kumaş desenleri elde edilmeye çalışılmıştır. Bu manada, ipekli dokuma kumaşlar, yaş bitki yaprakları ile direkt temas ettirilmek sureti ile başarılı bir şekilde desenlendirilmiştir. Ön terbiye işlemlerinde kullanılan yeşil sabun ve sodyum bikarbonat miktarının artması ile desenlendirme sonrası bir miktar daha net desenler elde edilmiştir. Fikseli ve fiksesiz kumaşların haslık değerleri arasında kayda değer farklılıklar gözlenmemiștir. Dolayısıyla, yapılan desenlendirme ișleminin, ilave bir fikse ișlemi gerektirmeyecek kadar bașarılı olduğu saptanmıştır. Yıkama ve bölgesel desenlendirme işlemleri kumaşın mekanik değerleri üzerinde bir miktar kayba yol açmıştır. Mevcut çalışma, değişik desen efektleri ve renk tonları elde etmek üzere; kullanılan bitki yapraklarının çeşitlerinin değiştirilmesi, ön / aynı banyoda / sonradan mordanlama yapılması, farklı aisidik ve bazik ișlem ortamlarının hazırlanması ile geliştirilebilir.

\section{Teşekkür}

Yazarlar, baskılı kumaşların fiksaj işlemlerinin gerçekleştirilmesinde yardımlarını esirgemeyen RAL Tekstil (Antalya) Üretim Müdürü R. Kıvanç Yakalı ve Rietveld Tekstil Serigrafi Baskı Firması (Antalya) Üretim Müdürü Nuray Polat'a teșekkür eder.

\section{Kaynakça}

[1] B. Smith, (1994). "The Future of Pollution Prevention An Alternative to Costly Waste Treatment, NC State University", http://infohouse.p2ric.org/ref/01/00386.pdf (Erişim Tarihi: 15.02.2017)
[2] Örün, E. 2015. Giysiler ve Çocuk Sağlığı: Ne Giysin? Nasıl Yıkansın?, Çocuk Sağlığı ve Hastalıkları Dergisi, 58: 43-49.

[3] Samanta, A. K., Agarwal, P. 2009. Application of Natural Dyes on Textiles, Indian Journal of Fibre\&Textile Research,34(4): 384-399.

[4] Lewis, H., Gertsakis, J., 2001. Design \& Environment: A Global Guide To Designing Greener Goods, Greenleaf, 141s.

[5] Niinimäki, K. 2006. Ekodesign and Textiles, RJTA, 10(3): 67-75.

[6] Clark, G.,Kosoris., J., Hong L. N., Crul, M. 2009. Design for Sustainability: Current Trends in Sustainable Product Design and Development Sustainability, 1, Redesign Case Study: Wai Tui, Fiji: 409-424.

[7] Dawson T. 2011. Progress Towards A Greener Textile Industry, Coloration Technology, Society of Dyers and Colourists, 128: 1 - 8.

[8] Duran, K., Duygu Özdemir, D., Namlıgöz, E. S. 2007. İpek Liflerindeki Serisinin Enzimatik Olarak Uzaklaştırılması, Tekstil ve Konfeksiyon, 3: 182-186.

[9] Başer, İ. 2002. Elyaf Bilgisi, Marmara Üniversitesi Yayınları, İstanbul, 90s.

[10] Duran, K., Bozacl, E., Karahan, H. A. 2007. Protein Esaslı Mamullerin Enzimatik Ön Terbiyesi, Tekstil ve Konfeksiyon, 3: 187-192.

[11] Chopra, S., Chattopadhyay, R., Gulrajani, M. L. 1996. Low Stress Mechanical Properties of Silk Fabric Degummed by Different Methods, 87(3): 542-553.

[12] Dawson, T. L., Hawkyard, C. J. 2000. A New Millenium of Textile Printing, Coloration Technology, 30(1): 7-20.

[13] Haar, S. 2011. EcoPrints: Dyeing and Printing with Plants Sustainable Practices for Color Effects Apparel, Textiles\&Interior Design; Agricultural Experiment Station Kansas State University.

[14] Kadolph, S. J., Diadick-Casselman, K. 2004. Inthebag: Contact Natural Dyes, Clothing and Textiles Research Journal, 22(1/2): 15-21.

[15] Flint, I. 2000. Arcadianal chemies, Textile Forum,19(1): 8-10.

[16] Öner, E. 2001. Tekstil Endüstrisinde Renk Ölçümü, Marmara Üniversitesi Yayınları No: 672, İstanbul, Türkiye.

[17] TS EN ISO 105-C06. Textiles For Colour Fastness - Part C06: Colour Fastness to Domestic and Commercial Laundering. Turkish Standards Institute, November 2001, Ankara, Turkiye.

[18] TS 717 EN 105 - X12. Textiles Tests for Colour Fastness - Part X12: Colour Fastness To 
rubbing. Turkish Standards Institute, February 2000, Ankara, Turkiye.

[19] Aniş, P., Çapar, G., Toprak, T., Yener, E. 2016. İpek Liflerinde Alternatif Çevre Dostu Yöntemlerle Serisin Giderme, Tekstil ve Konfeksiyon, 26(4): 368-374.

[20] Gururumurthy. B. R., Raj, S., Nachane, R. P.,
Radhalashmi, Y. C., Joseph, M. A. 2013. Effect of Fibre and Yarn Structural Parameters on the Mechanical Properties of Silk Suture Yarns, Journal of Textile Association, 2: 351-355.

[21] Coşkun, C., Karaca, E., Hockenberger, A., Ömeroğlu, S. 2016. İpek Ameliyat İplikleri ve Türkiye'de Üretim Olanakları, Tekstil ve Mühendis, 23(102): 140-152. 